\title{
DIET AND AWARENESS OF STUDENTS ABOUT HEALTHY EATING
}

\author{
A. Andonova* \\ Department of Health Care, Faculty of Medicine, Trakia University, Stara Zagora, Bulgaria
}

\begin{abstract}
An important factor influencing human health is food. The improvement of healthy nutrition is one of the leading principles for improving the health of the population. Forming habits for healthy nutrition in children should be realized as a shared responsibility between family, school and society.

MATERIALS AND METHODS: An anonymous study was conducted with 100 students aged between 14 and 18 years old, elected at random principle, with the informed consent of their parents.

PURPOSE: The purpose of the study is to know the level of awareness of students about the principles of healthy nutrition and their observance.

RESULTS: The study found out that $46 \%$ of students know the principles of healthy nutrition, and $26 \%$ - partially. Information about healthy nutrition $83 \%$ of students receive from family, $48 \%$ - from school, $45 \%$ - from the Internet, $41 \%$ - from television, 38\% - from friends. According to their selfassessment, $46 \%$ of the respondents know the principles of healthy nutrition, $30 \%$ follow them, and $49 \%$ strive to follow a healthy diet. According to $40 \%$ of students, the principles of healthy nutrition are followed by their families.

$16 \%$ have lunch in the school canteen every day, $26 \%$ bring healthy food from home every day, and $63 \%$ do not have breakfast.

According to $60 \%$ of the respondents, the healthiest foods are fruit and vegetables.

According to $68 \%$ of students, the most purchased foods outside school canteens are: burger sandwiches, gyros, bakeries, snacks, and beverages: carbonated drinks of world brands, energy drinks, and fruit juices without interest in the content of sugar and preservatives.
\end{abstract}

\section{INTRODUCTION}

Forming habits for healthy nutrition in children should be realized as a shared responsibility between family, school and society. Forming healthy models of nutrition and eating quality foods can be achieved through cultivating healthy nutritional habits from early age, as well as through timely control by state institutions and public organizations over children and students' foods and nutrition. The coordinated and joint efforts of all stakeholders, helped by common mechanism for control and education of adolescent nutrition will lead to the growth of healthy and employable people.

In Bulgaria, 5 national studies for nutrition and nutritional status of the population were conducted in the period 1997-2008. On the

\footnotetext{
*Correspondence to: Albena Andonova, Faculty of Medicine, Department of Health Care, Trakia University, Bulgaria, Stara Zagora, Str. Armeiska 11,e-mail: albena.andonova@trakia-uni.bg
}

ground of these studies, Ordinance № 37 of 21 July, 2009 for healthy nutrition of students is introduced, according to which, healthy nutrition of students is achieved by providing complete and various food, daily consumption of vegetables and fruit, adequate milk intake, dairy products, and other protein-rich foods, by increasing the consumption of whole grains, and limiting the intake of fat, sugar and salt (1). With a set of regulations, the state introduces regulations for the quality of food and nutrition of children in kindergartens and schools. (2-4) We are keeping on studies in this direction, in order to achieve an optimal level of quality of children's nutrition and hence better health.

Many international organizations are also actively working to improve the awareness of children and parents about forming healthy habits through various initiatives and projects (5-7). The flowing initiatives are very popular in Bulgaria: 
"Euro-Talk International" with European Day for Healthy Nutrition and Cooking with Children, Nestle Initiative - "For Healthier Children", National Network for Children, "School for Health - for Children, Parents and Teachers"(8), Projects with the support of the European Commission, etc.

The EU School Fruit, Vegetable and Milk Scheme have been applied since 1 August 2017, with improvement and increasing attention to children's health and education.

The aim is also to support the distribution of healthy products and the introduction of educational and information measures in schools. (9)

A WHO / World health organization / initiative presented its consecutive report about monitoring childhood obesity (COSI) at the end of 2018 (10). The report noted that regular breakfast, daily consumption of fruit and vegetables and limited consumption of sweet and salty foods, junk food and snacks, processed meat products, carbonated soft drinks "help reduce the risk of overweight and obesity.

In Bulgaria, children consume a lot of "junk" food, snacks, confectionery and salt, as $26 \%$ of children eat them more than three times a week, and $45 \%$ - at least once a week. There is also increased consumption of carbonated and soft drinks with high sugar content, as $18 \%$ of Bulgarian children drink them more than three times a week, and $65 \%$ - at least once a week. (11)

In 2018, a national study found twice as many obese children in 15 years, according to the UN Global Nutrition Report. Boys were more likely to have weight problems than girls, according to the report, as $33.6 \%$ of obese boys in Bulgaria aged between 5 and 19. For comparison, in 2000 they were $20 \%$.(12)

More than half of the students' day is spent at school. In most schools, there are canteens for whole-day meals, where hot food is prepared, in accordance with the state regulations. A preliminary weekly menu is prepared, where the caloric intake and the ratio between the individual food ingredients are calculated.

Food prices are low and allow families to finance the nutrition of children in school canteens. The students have the opportunity to buy: bottled natural mineral, spring and table water, natural $100 \%$ fruit and vegetable juices, fruit and fruit nectars, where the content of mono- and disaccharides does not exceed $20 \%$, milk, milk drinks containing fat up to $2 \%$ fruit and herbal tea, hot chocolate.

It is forbidden to offer in schools fried potatoes and cereals, extruded cereals with added fat, fried nuts, fried pasta, confectionery and chocolate products, except chocolate, sweets with high fat and sugar content, syrupy sweets, dry soups and dry broths.

Health education and motivation for a healthy lifestyle should start in childhood and actively continue in kindergarten and schools, as these measures should be based on scientific research (13-16). The role of parents is a key factor in reproducing and maintaining proper nutrition and exercising in children. Teachers and medical experts, working in kindergartens and schools are also an important factor in health education and informing nutritional habits. Excellently trained medical experts, working in primary medical care, kindergartens and schools should be the main motivator and source of knowledge informing persuasions and habits for a healthy lifestyle in children and their families (17-19).

The knowledge gained in medical universities must continue to be upgraded in postgraduate education. The use of modern methods and tools for training and communication with children, and parents combined with the provision of quality food, physical activity, work and rest are the basis in forming desire for a healthy lifestyle. Conducting regional and national studies is very useful for improving children's health (20-23).

\section{PURPOSE}

The purpose of the study is to know the level of awareness of students about the principles of healthy nutrition and their observance. The survey data were processed with mathematical and graphical methods - Microsoft Office Excel 2003.ink.

\section{MATERIALS AND METHODS}

An anonymous study was conducted with 100 students aged between 14 and 18 years old, elected at random principle, with the informed consent of their parents.

\section{RESULTS AND DISCUSSION}

Teenagers have already formed certain ideas and nutritional habits built in the family, 
school and through the media. At this age of physical and mental maturation and rapid changes in physics, young people very often under the influence of various fashion trends tend to apply different diets that are not particularly useful for their age and physical development.
That is why the first question in the study was aimed at revealing their main source of information about healthy nutrition. High share - $83 \%$ of the respondents indicated their family, $48 \%$ - school, $45 \%$ receives information from the Internet, $41 \%$ from television, $38 \%$ from friends.

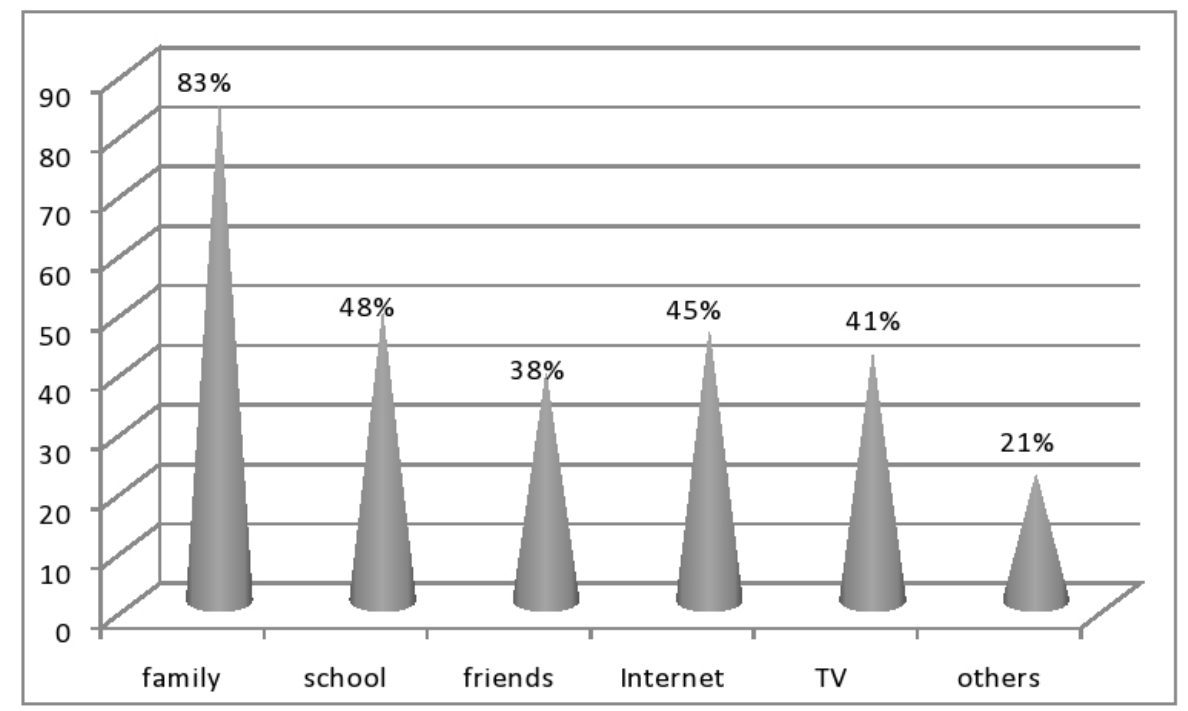

Figure 1. Main sources of information

According to the students' self-assessment, $46 \%$ fully know the principles of healthy nutrition, and $26 \%$ - partially. $30 \%$ define their diet as healthy, $49 \%$ strive to eat healthy foods, the rest of the respondents note that they consume what they like. The data analysis shows that despite declaring that they know healthy foods, a small part of the students consume them. The group of partially consuming healthy foods predominates. It should not be missed the fact that some students do not know and do not want to follow the principles of healthy nutrition.

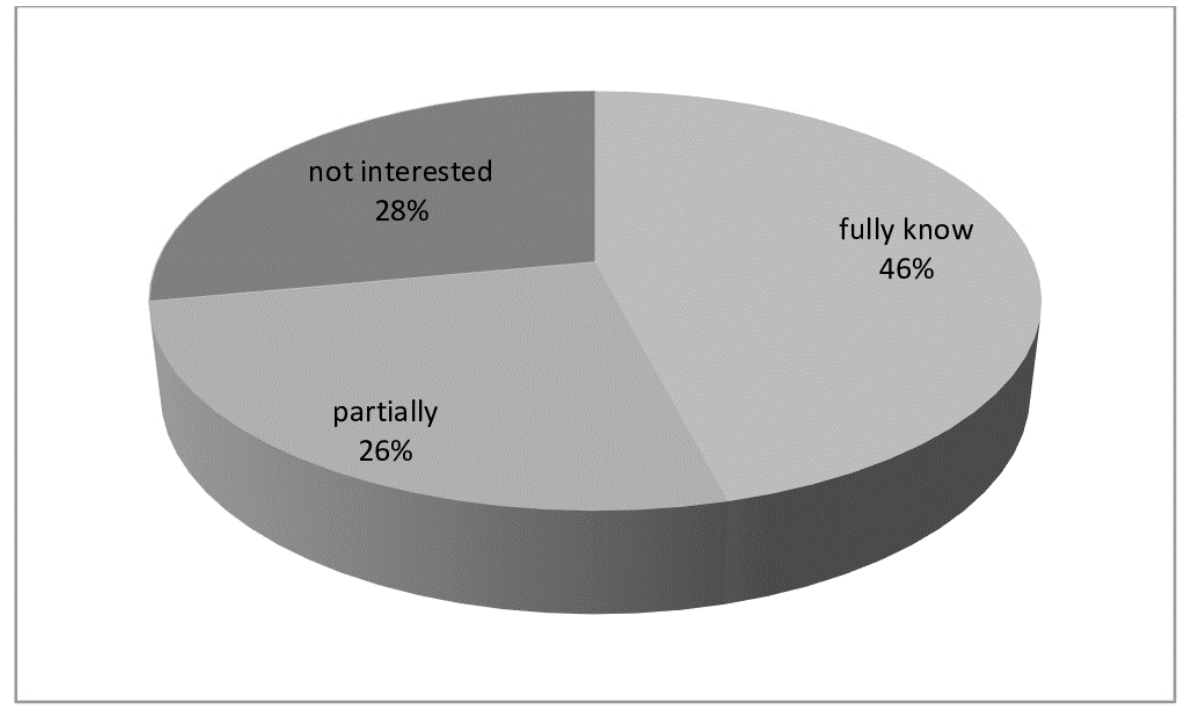

Figure 2. Students' self-assessment of knowledge of the principles of healthy eating

Low share of respondents eat in the school canteen: $16 \%$ have lunch daily, $20 \%$ buy fruit,
$45 \%$ buy water and milk drinks twice a week. Also low percentage - $26 \%$ brings healthy food from home every day. 


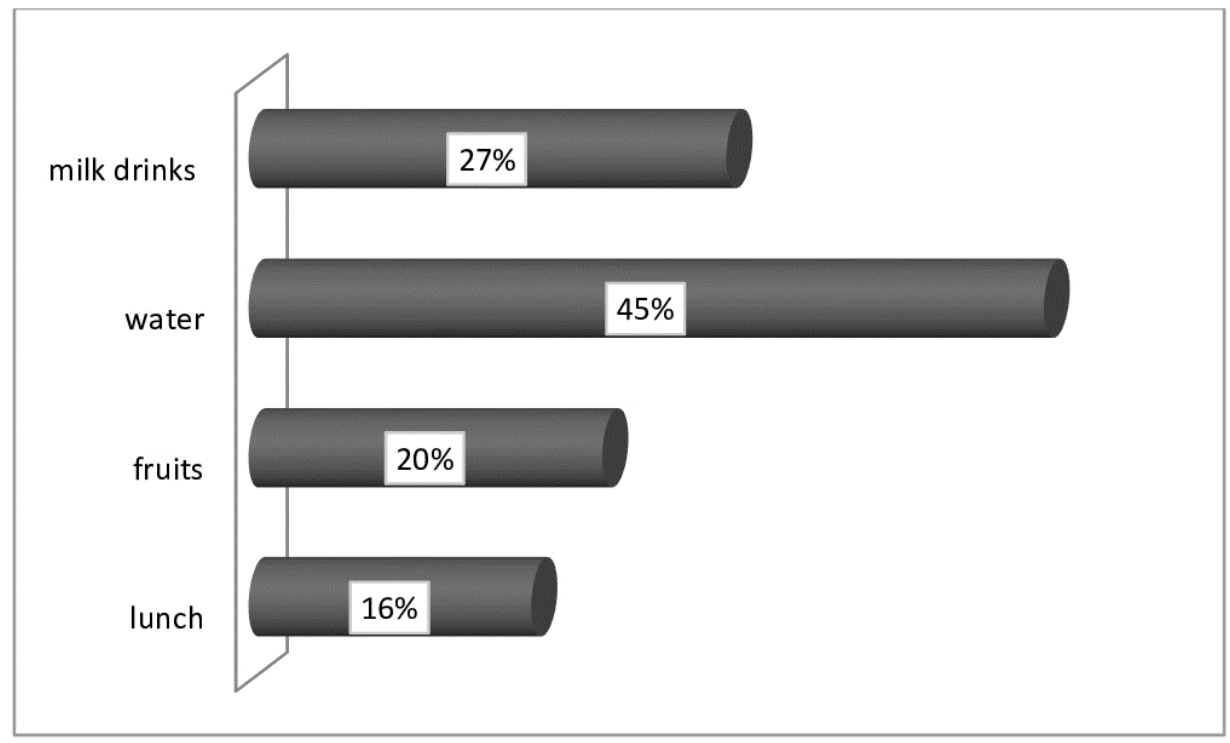

Figure 3. Most purchased food from students in the school canteen

To the question "What do you have for breakfast at school?", the most numerous (63\%) group answers "nothing".

The most bought foods outside the school canteens by $68 \%$ of the students are - fast food /burger sandwiches, gyros, pasta, snacks/. The most bought beverages are carbonated drinks of world brands, energy drinks and fruit juices without interest in the sugar content.

According to $60 \%$ of the respondents, the most useful foods are fruit and vegetables. The most preferred of them are bananas, and from the seasonal fruit - strawberries, watermelons, cherries. The most preferred vegetables are tomatoes and cucumbers.

Although students know healthy foods, they do not eat them daily. Only $14 \%$ of the respondents took the opportunity to explain their behaviour. The most common answer is that they do not overdo with harmful foods, which do not affect negatively their body.

\section{CONCLUSION}

1. The study found out that $46 \%$ of students know the principles of healthy nutrition, and $26 \%$ - partially. Information about healthy nutrition $83 \%$ of students receive from family, $48 \%$ - from school, $45 \%$ - from the Internet, $41 \%$ - from television, $38 \%$ - from friends.

2. According to their self-assessment, $46 \%$ of the respondents know the principles of healthy nutrition, $30 \%$ follow them, and $49 \%$ strive to follow a healthy diet.
3. According to $40 \%$ of students, the principles of healthy nutrition are followed by their families.

$16 \%$ have lunch in the school canteen every day, 26\% bring healthy food from home every day, and $63 \%$ do not have breakfast.

4. According to $60 \%$ of the respondents, the healthiest foods are fruit and vegetables.

5. According to $68 \%$ of students, the most purchased foods outside school canteens are: burger sandwiches, gyros, bakeries, snacks, and beverages: carbonated drinks of world brands, energy drinks and fruit juices without interest in the content of sugar and preservatives.

\section{REFERENCES}

1. Ordinance № 37 of 21 July 2009 on healthy nutrition of students in force since 15.09.2009 Issued by the Minister of Health.

2. Ordinance amending and supplementing Ordinance № 9 of 2011 on the specific requirements for food safety and quality offered in kindergartens, school canteens and retail outlets on the territory of schools and kindergartens, as well as for food, offered at organized events for children and students (SG, issue 73 of 2011). Prom. DV. issue 81 of October 2, 2018

3. Ordinance № 1 of 22 January 2018 on the physiological norms for nutrition of the population Ministry of health ordinance № 1 of 22 January 2018 on the physiological norms for nutrition of the population, SG No. 11, dated 2.02.2018.

4. Ordinance № 8 of December 4, 2018 on the specific requirements for the safety and 
quality of food offered in kindergartens, school canteens and retail outlets on the territory of schools and kindergartens, as well as food offered at organized events for children and students, SG number: 104, dated 14.12.2018

5. UNICEF. Children, Food and Nutrition: Growing Well in a Changing World. New York. 2019. 255 p.

6. WHO. Regional Office for Europe. European Food and Nutrition Action Plan 2015-2020, WHO 2015

7. Healthy eating for students from 7 to 19 years. Developed the Recommendations for Healthy Eating: http://www.mh.government.bg/media/filer_ public/2015/04/08/zdravoslovno-hraneneuchenici-17-19g.pdf

8. The Bulgarian Association for the Study of Obesity and Related Diseases

9. www.basord.com

10.European Commission. Food, Farming, Fisheries. School scheme explained.

11.https://ec.europa.eu/info/food-farmingfisheries/key-policies/common-agriculturalpolicy/market-measures/school-fruitvegetables-and-milk-scheme/schoolscheme-explained_en

12.WHO European Childhood Obesity Surveillance Initiative (COSI) https://www.euro.who.int/en/healthtopics/diseaseprevention/nutrition/activities/whoeuropean-childhood-obesity-surveillanceinitiative-cosi

13. National Network for Children. https://childhub.org/bg/child-protectionnews/blgariya-szo-nablyudavauvelichavane-na-zatlstyavaneto-inadnormenoto-teglo

14.Country overview Malnutrition burden https://globalnutritionreport.org/resources/n utrition-profiles/europe/easterneurope/bulgaria/\#profile

15.Ivanov, E., The health culture of students a factor for effective health promotion, Gorex Press. Sofia, Bulgaria. 2016
16. Mladenova, S., Health Education, Arctic 2001, Sofia, Bulgaria, 2009.

17.Paskaleva, R., Ivanova, V. and Pavlova, V. Study of physical development in children of pre-school age. Management and education. 14:126-131, 2018

18.Paskaleva, R., Uzunova, A., and Radev, S. Early diagnosis and prevention of spinal deformities in kindergarten. Activities in Physical Education and Sport, 5(2): 163166, 2015

19.Miteva, Kr., The training process for building the professional competencies of medical professionals. Sestrinsko delo.1-2: 47-51,2011

20.Kyuchukova S., Nutrition and future nurses, XXX Scientific and Technological Session. KONTAKT 2012, ed. TEMOTO, pp. 190-192, 2012

21.Ivanova N. and Penkova, M. Professionalclinical thinking and solving the medical and social problems of the population. XXXIII Scientific and Technological Session. KONTAKT 2014, ed. TEMOTO, pp. 317-319, 2014

22. Atanasova, Z. and Miteva, Kr., Formation of communication skills in the preparation of students in "Health Care". Health Care,1:21-27, 2009

23. Kyuchukova, S., Health knowledge - a guide for children deprived of parental care, XXXV Scientific and Technological Session. KONTAKT 2015, ed. TEMOTO, pp. 206-210, 2015

24.Nikolova, M., Participation of students majoring in "nurse" in the health education of children placed in homes for medical and social protection. XXXVI Scientific and Technological Session. KONTAKT 2015, ed. TEMOTO, pp. 320-322, 2015

25.Nikolova, M., Students and their motivation for work. XXXVIII Scientific and Technological Session. KONTAKT 2016, ed. TEMOTO, pp. 234-237, 2016 